\title{
The New EU Directive on the Use of Animals for Research and the Value of Moral Consistency
}

\author{
Jan Deckers
}

Received: 31 July 2012 / Accepted: 30 August 2012 / Published online: 12 October 2012

(C) Springer Science+Business Media B.V. 2012

Beginning in 2013, the European Union (EU) Directive 2010/63/EU on the protection of animals used for scientific purposes must be implemented by member states (European Parliament and the Council of the European Union 2010). This editorial aims to reveal a moral inconsistency underlying EU legislation on the use of animals and to prepare for further reform in laws that govern the use of animals worldwide.

In his recent book on the ethics of animal experimentation, Andrew Knight estimates that at least 126.9 million animals with vertebrates were used in experiments in 2005 (Knight 2011, 16). According to the organisation Animals Deserve Absolute Protection Today and Tomorrow (ADAPTT 2012), the number of animals who are killed for human food every year exceeds 150 billion. However, this is considered to be a very conservative estimate based on available data gathered in 2003. For every animal used in experiments, it is therefore likely that at least 1,200 animals are killed to provide food. These statistics are mentioned here not from a desire to show that the number of animals used for research is relatively insignificant compared to the number of

J. Deckers $(\bowtie)$

School of Medical Sciences Education Development,

Newcastle University,

England NE2 4HH, UK

e-mail: jan.deckers@ncl.ac.uk animals used for food, but, rather, to point out a glaring inconsistency: Whilst fairly stringent legal codes have been developed to regulate the activities of experimenters who work in a sector that uses relatively few animals, legal codes continue to turn a blind eye to the vast numbers of animals who are being used for food.

In most EU legislation, the articles that form the core of the legal text are preceded by a number of recitals that provide reasons underpinning the law. Directive 2010/ $63 /$ EU is a remarkable legal document, particularly because of recitals 10 and 12. Recital 10 states that "this Directive represents an important step towards achieving the final goal of full replacement of procedures on live animals" (European Parliament and the Council of the European Union 2010). Recital 12 posits that "the use of animals for scientific or educational purposes should ... only be considered where a non-animal alternative is unavailable" (European Parliament and the Council of the European Union 2010). The reason why these recitals are so interesting is that they would have drastic implications for the use of animals for food, if people were prepared to be consistent. This is clear if we replace a few key words in recital 12: "the use of animals for" food "should ... only be considered where a non-animal alternative is unavailable." Indeed, the "final goal of full replacement" that recital 10 talks about seems to be within the reach of most people who live in the European Union today: Most people have sufficient non-animal alternatives available to feed 
themselves. Provided that they make sure their diets are well-planned, they would be healthy; at least that is the view of the American Dietetic Association and the Dietitians of Canada (2003).

If individuals and families were sufficiently interested, it is plausible to assume that most people living in the European Union, as well as many who live in other places, would be able to access adequate nutrition to maintain good health. The consumption of animal products can be replaced by the consumption of other things, but most people fail to do so simply because they are reluctant to change habits or because they like the taste.

In the core of the legal text, paragraph $\mathrm{d}$ of article 38 stipulates that all project evaluations must satisfy "a harm-benefit analysis ... to assess whether the harm to the animals in terms of suffering, pain and distress is justified by the expected outcome" (European Parliament and the Council of the European Union 2010, art. 38, para. d). Whereas the law fails to provide clear guidance on when the harm might outweigh the benefits, it is likely that any research proposal that aims to perform an experiment involving the killing of animals to find out how much extra enjoyment people might obtain from eating animal products compared to eating plant foods would fail any plausible "harmbenefit analysis" that is in line with the spirit of this law. It is also extremely plausible that other potential objectives, such as the desire to keep people in their jobs or to provide enjoyment to those who like to experiment on animals, would fail to tip the balance in favour of the benefits for any research ethics committee engaged with "a harm-benefit analysis."

A plausible reading of the reasoning underlying this law would therefore support the vegan project (which I have outlined in earlier work) that aims to create legal reform that would prohibit the consumption of nearly all animal products (Deckers 2010a, 2011a, in press). Its basic contention is that food practices that rely on the killing of animals should be banned wherever human beings are able to enjoy adequate alternatives that produce fewer negative Global Health Impacts (GHIs). Adopting this project does not imply that killing an animal is always wrong. In line with article 17, paragraph 2, of the new Directive it can accept, for example, that it may be appropriate to kill animals who are "likely to remain in moderate or severe pain, suffering, distress or lasting harm" (European Parliament and the Council of the European Union 2010, art. 17, para. 2).
The necessity to adopt the vegan project gains further strength when we compare the harms imposed upon human beings because of animal research versus the human harms associated with the consumption of animal products. Although the emotional harm that humans who experiment on animals may undergo should not be underestimated (Knight 2011, 167175), the consumption of animal products, at least in part because of the difference in scale, imposes a vastly greater range of very significant negative GHIs on humans. Psychological harm is not only suffered by those who work in animal laboratories but also by those who work in slaughterhouses and other infrastructures associated with the consumption of animal products (Dillard 2008). Moreover, even if it cannot be stated unequivocally that the consumption of all animal products undermines human health, much research indicates that the overconsumption of a wide range of animal products contributes to illness, including cancer and cardiovascular disease (World Cancer Research Fund and American Institute for Cancer Research 2007; Key et al. 2009; Lloyd-Williams et al. 2008). Many hazards that are produced by the farm animal sector affect not only those who consume animal products, but others as well. Pandemic flu is just one example of an assortment of diseases that are likely to emerge and spread when animals are kept in intensive farms that provide rich havens for the development of new pathogens (Deckers 2011b), and many diets that include animal products contribute more to the negative GHIs posed by climate change and myriad other environmental dangers, for example, contamination of waterways and air pollution (Deckers 2010b; 2011c). Many of these diets also increase the likelihood of some people suffering from hunger, including those who are unable to buy food due to high food prices and those who are denied access to land and other resources that are required to produce food. This is so because the farm animal sector uses a relatively larger quantity of a wide array of resources than other food sectors to produce a comparable amount of food, thus increasing competition over scarce resources-including land, rock phosphate, water, and oil-based products such as fertilisers (Deckers 2011d).

The principle of nonmaleficence is widely accepted by bioethicists, but few have questioned whether supporting practices that contribute to ill health and potentially produce new zoonoses that could impact 
upon millions of people fails to give adequate consideration to this, even if the probability of some adverse effects might be relatively low.

Finally, there is at least one more reason why the moral schizophrenia that underlies our laws related to the use of animals must be resolved: The lives of animals used in research will continue to be regarded as cheap unless people embrace the vegan project. When the vast majority of the human population continues to consume animal products even where adequate alternatives that produce relatively few negative GHIs are available, it is highly unlikely that researchers will face great opposition when arguing that animal research is "necessary." In a world wherein many people are prepared to support practices that involve the killing of animals for trivial purposes, it is very improbable that serious resistance will arise against the views of experts who have been trained in the art of justifying their methods in terms of "need." In this light, it should not come as a surprise that a significant number of those involved in the research industry resist the use of alternatives, are careless in their study designs, and are reluctant to engage in serious study of previous work (resulting in needless duplication) (Knight 2011, 98).

Whereas the articles of Directive 2010/63/EU focus mainly on animal welfare, its recitals question the use and the killing of animals for unnecessary research. Moral consistency demands that new EU law be passed to prevent billions of animals from being killed completely unnecessarily. Other jurisdictions that agree that animals should not be used for unnecessary research ought to bring about similar reform.

\section{References}

American Dietetic Association and the Dietitians of Canada. 2003. Position of the American Dietetic Association and Dietitians of Canada: Vegetarian diets. Journal of the American Dietetic Association 103(6): 748-765.
Animals Deserve Absolute Protection Today and Tomorrow (ADAPTT). 2012. More than 150 billion animals slaughtered every year. http://www.adaptt.org/killcounter.html. Accessed July $31,2012$.

Deckers, J. 2010a. What policy should be adopted to curtail the negative GHIs associated with the consumption of farmed animal products? Res Publica 16(1): 57-72.

Deckers, J. 2010b. Should the consumption of farmed animal products be restricted, and if so, by how much? Food Policy 35(6): 497-503.

Deckers, J. 2011a. Should Whiteheadians be vegetarians? A critical analysis of the thoughts of Hartshorne and Dombrowski. Journal of Animal Ethics 1(2): 195-209.

Deckers, J. 2011b. Could some people be wronged by contracting swine flu? A case discussion on the links between the farm animal sector and human disease. Journal of Medical Ethics 37(6): 354-356.

Deckers, J. 2011c. Justice, negative GHIs, and the consumption of farmed animal products. Journal of Global Ethics 7(2): $205-216$.

Deckers, J. 2011d. Does the consumption of farmed animal products cause human hunger? Journal of Hunger and Environmental Nutrition 6(3): 353-377.

Deckers, J. In press. In defence of the vegan project. Journal of Bioethical Inquiry 10(2).

Dillard, J. 2008. A Slaughterhouse nightmare: Psychological harm suffered by slaughterhouse employees and the possibility of redress through legal reform. Georgetown Journal on Poverty Law \& Policy 15(2): 391-408.

European Parliament and the Council of the European Union. 2010. Directive 2010/63/EU of the European Parliament and of the Council of 22 September 2010 on the protection of animals used for scientific purposes. Official Journal of the European Union L 276, vol. 53: 33-79.

Key, T., P. Appleby, E. Spencer, R. Travis, N. Allen, M. Thorogood, and J. Mann. 2009. Cancer incidence in British vegetarians. British Journal of Cancer 101(1): 192-197.

Knight, A. 2011. The costs and benefits of animal experiments. New York: Palgrave Macmillan.

Lloyd-Williams, F., M. O'Flaherty, M. Mwatsama, C. Birt, R. Ireland, and S. Capewell. 2008. Estimating the cardiovascular mortality burden attributable to the European Common Agricultural Policy on dietary saturated fats. Bulletin of the World Health Organization 86(7): 535541.

World Cancer Research Fund and American Institute for Cancer Research. 2007. Food, nutrition, physical activity, and the prevention of cancer: A global perspective. Washington, D.C.: American Institute for Cancer Research. 